\title{
Re-integration: a new standard in first responder peer support
}

\author{
Glen Klose,* Colleen Mooney,* Doug Mcleod*
}

\begin{abstract}
Since its inception, the Edmonton Police Service (EPS) Re-integration Program has grown in its capacity, impact, and service to members within EPS. It has also attracted increasing attention among-and emulation by-other first responder communities in the province of Alberta. Most recently, the program was the subject of a featured segment during the joint Canadian Association of Chiefs of Police (CACP) and Mental Health Commission of Canada (MHCC) international conference, "The Mental Health of Police Personnel: What We Know \& What We Need to Know and Do", held in February 2017. Based on the strong reception and interest generated among conference delegates, the Journal of CSWB invited the program's architects to develop the following Practice Guideline article, with a view to bringing wider awareness to this unique peer-supported program. The EPS program connects conventional counselling and support resources with aspects of recovery and re-integration that are more closely tied to the equipment and operational realities of first responders.
\end{abstract}

Key Words Police; first responders; PTSD; peers.

Journal of CSWB. 2017 June;2(2):55-57

www.journalcswb.ca

\section{INTRODUCTION}

Constable Doug McLeod sat in a classroom at the shooting range with his hat pulled down low. It was October of 2013 and, despite being in the room for some time, McLeod had not yet taken off his coat. He was nervous, running his fingers through his hair and scratching his beard. Across the room in a locked case was McLeod's service pistol, which he had almost used to end his life five months earlier. He knew that gun was in the room with him, and it made him agitated and anxious. All he wanted to do was to return to police work but, at this moment, he did not know how to make that happen.

Sergeants Glen Klose and Colleen Mooney (then Constables) were in the room with him. They had assisted Doug through an officer-involved shooting the year before and knew of his prior experiences as a soldier with the Canadian Forces. They also knew that Doug's Post Traumatic Stress Disorder diagnosis was due to his experiences as a medic, a soldier, and an Edmonton police officer. While they were both aware of Constable McLeod's unquestioned bravery, none of them realized that this classroom meeting would ultimately become the first step in an innovative program to incorporate peer support into the treatment of psychological injuries.

\section{The Program}

The Edmonton Police Service (EPS) Re-integration Program began in 2009 when Sergeant Kent Hughes recognized the need to better assist police officers after an officer-involved shooting (OIS). The initial program helped another Edmonton officer return to work after he had been shot in June of 2006, and Sgt. Hughes wanted to formalize the process. He approached firearms instructors at the EPS Nixon Training Facility, and the Re-integration Program quickly began to grow.

The initial program was modeled after one from the Irish National Police, and was designed to get officers comfortable behind the gun after an officer-involved shooting. The psychological and physiological effects of a lethal force encounter are significant, and officers need to have these feelings normalized for themselves in the days and weeks after their OIS.

The re-integration process involves a series of steps that gradually builds to the officer firing his or her firearm in a safe and controlled environment. The key element of the program is that the affected officer controls the pace and depth of their retraining, with no judgment, no assessment, and no agenda by members of the Re-integration Team. The primary objective of the program is to see officers return to work with confidence, and with a new gun. In most cases, their old gun is seized for the purposes of the OIS investigation.

The process involves 7 stages, all conducted at the individual officer's pace:

Stage 1: Initial meeting.

Stage 2: Physical dexterity of firearm in a 'dry capacity". 
Stage 3: Acclimation to live gunfire.

Stage 4: Officer fires live rounds

Stage 5: Officer-directed training.

Stage 6: Re-introduction to normal training and eventual requalification.

Stage 7: Follow-up with the officer at the one-month, threemonth and one-year anniversary.

In Edmonton, police officers involved in an officerinvolved shooting are mandated to complete re-integration prior to being cleared by the organizational psychologist for active duty. This also applies to officers who were in a position to shoot and did not, or could not. It was determined early on that best practice was to have two members of the re-integration team work with the involved officer-one to facilitate the re-integration process, and one to watch the police officer for physiological and psychological signs of stress.

As the success of the program grew, there was a need for additional members to assist. New members of the team would have to have operational credibility, the ability to teach firearms skills, and an awareness of the psychological stress that members would face after an OIS. By the time of Doug McLeod's shooting in the winter of 2012, the team had grown to five employees.

\section{The Doug McLeod Story}

In December of 2012 McLeod was in an officer-involved shooting along with three of his squad mates during a traffic stop in West Edmonton. None of the officers were physically hurt, and all four went through the Re-integration Program in the weeks after the shooting. After a few months, alone one night, McLeod nearly took his own life while seated in his patrol car.

Thankfully, McLeod found the strength to ask for help. The West Edmonton shooting he was involved with became a catalyst to bring back unresolved issues from his time as a military medic repatriating Canadian soldiers from Afghanistan.

McLeod received the initial psychological help he needed and eventually entered a Traumatic Psychological Injury Program through the Alberta Worker's Compensation Board and the Millard Treatment Centre in Edmonton. With the assistance of his Psychologist and Occupational Therapist, he began the long road to recovery. Months into the process, McLeod and his treatment provider recognized that the Millard Centre did not have the proper infrastructure in place-specifically, access to firearms-to ultimately return him to work as a police officer. Not one to accept the statusquo, McLeod reached out to Cst. Klose and Cst. Mooney for assistance.

It took about two months of regular meetings between McLeod, Klose, and Mooney to get a gun back in McLeod's hands. As time progressed, so did his skill level and his confidence. By the five-month mark, McLeod was a better shooter than he had ever been, and the gun stopped being a symbol of how he was going to end his life. Instead, it was once again a tool, no different than a hammer or a wrench.

From there, the three worked on additional officer safety skills to increase McLeod's confidence as an active police officer. To achieve this, the three would go out in a patrol car, seeking whatever interactions McLeod felt he needed on a given day. The three officers would respond to calls with a dual focus: dealing with the event itself, and re-introducing McLeod to the rigors of police work. Klose and Mooney worked out a process where one of them would focus on the call itself, while the other would monitor McLeod's physiological and psychological responses. These days on the road restored McLeod's hunger for policing and, not long after, McLeod returned to operational duties as a beat officer in West Edmonton.

McLeod's efforts to help overcome the barriers he had faced brought about a new understanding of the need for an approach that created a specific re-integration plan for each individual officer. It also showed that peers played a greater role in the effective return to work of injured officers than was previously understood, especially through the exposure that peers could provide to real work environments.

Although the three knew that they were forging new ground, none of them understood in those first few months that they were building the foundation of the Re-integration Program. Logically their approach made sense; the Worker's Compensation Board, occupational therapists, and psychologists didn't have access to police equipment like guns, duty belts, cell blocks, rams, or police dogs. Further, clinicians have limited ability to see police-specific situations through a police officer lens. Cops can relate to other cops and can give perspectives, advice, and encouragement that clinicians may not be able to match. The need for a dedicated peer program was never recognized until McLeod stepped up and asked for a more specific type of assistance.

The Program is now generally referred to as the 'Edmonton Model'. It is characterized by high levels of cooperation and coordination between the members of the Re-integration Team, the Worker's Compensation Board, occupational therapists, psychologists, psychiatrists, disability management coordinators, and Human Resources staff from within the EPS. The integrity of the program is maintained through oversight by the officer's clinicians and the on-staff EPS Organizational Psychologist.

The program has also evolved into "short term" postshooting re-integration program and a "long-term" version, with the shorter program only taking a few hours or days. Officers requiring more assistance are put into the longer term, which can take up to six months.

In addition to assisting officers after an Officer Involved Shooting or PTSD diagnosis, members of the Re-integration Team have worked with officers after fatal collisions, fatal Conductive Energy Weapon deployments, and other critical incidents. Officers who have come through the program are encouraged to replicate aspects of his or her critical incident to reconcile their feelings around it. This might mean driving a police vehicle onto a shooting range and allowing the officer to shoot from the car, or listen to the sound of a barking dog while the officer shoots his or her weapon. It might also mean hearing the cycling of a conductive energy weapon several times until the sound no longer creates high levels of stress in the officers. Since every person is different, so too are their processes to return to work.

The success with McLeod and other officers with a PTSD diagnosis led Klose and Mooney to reach-out to Edmonton-based paramedics and the Alberta RCMP. It was recognized that these new peer-focused treatment options 
could be applied to other first-responder communities, as well. Specially trained medics are in the best position to assist other medics who are struggling with mental health injuries or illnesses, as they have insights into the work of a paramedic and access to the stretchers, IV's, and ambulances. This same concept applies to firefighters, soldiers, prison officers, and courthouse sheriffs.

Currently, the EPS Re-integration Team consists of 13 members, chosen for their commitment to training and their passion as advocates for first-responder mental health initiatives. Each member must recognize the need for confidentiality and how even a single breach could undermine the program. Team members have backgrounds in police training and are certified in Group and Individual Crisis Intervention from the International Critical Incident Stress Foundation. Each member has also taken a Re-Integration Course, created by Klose and Mooney. Currently, members on this team are activated on an 'as need' basis, with the majority working with officers in the 'long term' Program.

Since 2015, Re-integration Team members have taught four courses to show other organizations how to better support their employees through the use of peer-driven exposure therapy. As mentioned earlier, it is essential that the injured officer controls as much of the process as possible.

As most organizations already have the correct infrastructure in place to assist officers with peer-driven exposure therapy, Klose and Mooney have found that the only real resource needed to facilitate a program such as this is time. Team members must be granted the time to work with those who are struggling.

In total, Re-integration Team members have worked with approximately 95 officers in both the short-term and long-term programs. Further, Alberta Health Services and the Alberta RCMP have now launched very successful Re-integration Programs based on the EPS model. Alberta Health Services are on the cusp of making the EMS Re-integration program province-wide after a successful pilot in the Edmonton Zone, and the RCMP are researching a national re-integration strategy.

Despite some setbacks that he has weathered well, McLeod is back to work on a full-time basis. He routinely meets with Klose and Mooney to speak about how the Re-integration Program can continue to grow and develop. As these three officers have learned, there can be a better way to assist officers who want to come back to the careers they love.

\section{CONFLICT OF INTEREST DISCLOSURES}

On behalf of the authors, Glen Klose declares that there are no conflicts of interest associated with the publication of this article.

AUTHOR AFFILIATIONS

${ }^{*}$ Edmonton Police Service, Edmonton, AB, Canada. 